\title{
Descolonizar a sexualidade: Teoria Queer of Colour e trânsitos para o Sul*
}

\author{
Caterina Alessandra Rea** \\ Izzie Madalena Santos Amancio***
}

\section{Resumo}

Este texto pretende analisar os desafios do trânsito da teoria queer nos contextos brasileiro e do chamado Sul global. Como pensar essa recepção sem repetir a oposição entre um Norte central $e$ produtor, e um Sul periférico e receptor? Após apresentarmos um estado da arte relativo às produções brasileiras no campo da teoria queer, avançaremos a hipótese de que a Crítica Queer of Colour poderia facilitar esse trânsito. Considerando as questões de gênero e sexualidades enquanto inseparáveis da história pós/neocolonial do Ocidente (racismo, imigração, imperialismo), essa teoria constitui uma voz radical que se opõe ao conformismo de muitos grupos LGBT, na maioria dos países centrais.

Palavras-chave: Interseccionalidade, Raça, Pós-Colonial, Teoria Queer, Sexualidades.

* Recebido em 07 de janeiro de 2016, aceito em 02 de abril de 2018.

** Professora do Instituto de Humanidades e Letras, da Universidade da Integração Internacional da Lusofonia Afro-brasileira, São Francisco do Conde, Bahia, Brasil. caterina@unilab.edu.br / http://orcid.org/0000-0001-6868-6668

*** Bacharel em Humanidades e Graduanda em Terminalidade em Pedagogia, Instituto de Humanidades e Letras, da Universidade da Integração Internacional da Lusofonia Afro-brasileira, São Francisco do Conde, Bahia, Brasil. izzie.mada@outlook.com.br 
Decolonizing Sexuality:

Queer theory of color and movements to the South

\begin{abstract}
This paper analyzes challenges linked to the circulations of queer theory in the context of Brazil and the so-called Global South. How can this reception be considered without repeating the opposition between a central and productive North and a peripheral and receptive South? After presenting a state of the art about Brazilian literature in the field of Queer Theory, we present the hypothesis that Queer of Color Critique could help this circulation of ideas. By considering issues of gender and sexualities to be inseparable from the post/neo-colonial history of the West (racism, immigration, imperialism), Queer of Color Theory represents a radical voice in opposition to the conformism of many LGBT groups, in the majority of central countries..
\end{abstract}

Keywords: Intersectionality, Race, Post-Colonial, Queer Theory, Sexualities. 


\section{Introdução}

O processo de trânsito e deslocamento da teoria queer, suas principais ideias e práticas teóricas, do Norte para o chamado Sul global e, particularmente, América Latina e África, vem suscitando, nos últimos anos, um intenso e interessante debate, que tentaremos dar conta nestas páginas. A partir das reflexões aqui desenvolvidas, é nossa intenção questionar os binômios $e$ oposições entre Norte e Sul, enquanto lugares geográficos e simbólicos supostamente separados. Nessa direção, pretende-se estabelecer diálogos entre os que chamaremos de diferentes "suis", não necessariamente no sentido geográfico, mas metafórico, político e estratégico. Em um sentido mais amplo, tais suis incluem as produções de pensamento elaboradas nas novas $e$ velhas diásporas, a criatividade $e$ a efervescência das comunidades migrantes nos países do Norte, no seio das quais o passado é ressignificado, tecendo identidades e experiências complexas e plurais. Trata-se, por exemplo, dos movimentos sociais, políticos e intelectuais do chamado "Terceiro-Mundo estadunidense", do qual fala a chicana Chela Sandoval (2011), ou das minorias racializadas na Europa, que Fatima El Tayeb chama de outr@s europe@s, em busca de estratégias de descolonização do feminismo $e$ de enfrentamento dos padrões da heteronormatividade branca (El Tayeb, 2011). Enquanto lugar de subalternidade continuamente ressignificado, as teorias $e$ as práticas queer fazem parte dessas experiências culturais antihegemônicas, de contestação da sociedade normativa e das suas múltiplas formas de exclusão.

Entendemos, por teoria queer, um conjunto de produções teóricas e de práticas de ativismo voltado para a contestação e a desconstrução de normas sócio-sexuais. A teoria queer afirma-se no começo dos anos 1990 (Teresa de Lauretis, Judith Butler) em oposição à política da igualdade, segundo a qual mulheres $e$ minorias sexuais deveriam se integrar na sociedade dominante. Em oposição à ideia de uma assimilação de mulheres e minorias sexuais ao sistema social atual, a teoria queer vê, nesses grupos, 
sítios de contestação social e de desconstrução política das normas majoritárias (não somente em termos de gênero e sexualidade, mas também em termos de raça, classe, nacionalidade e, em geral, das normas corporais). Para a teoria queer, as minorias sexuais deveriam permanecer em um lugar estratégico de luta, resistindo à tentação de se uniformizar e se integrar ao conforto da maioria e da sociedade capitalista, como um todo. A teoria queer baseia-se na politização da dissidência sexual e das sexualidades contra-hegemônicas e defende uma política das identidades não essencializadas. A identidade tem um valor estratégico para formular reivindicações radicais, para pautar ações políticas, mas ela deve ser considerada como uma construção dinâmica $e$ mutável, sempre historicamente transformada e renegociada, $e$ não como uma realidade estável, fixa e natural. Ela é uma estratégia e não uma essência. Nesse sentido, a identidade queer afirma-se enquanto oposição à norma estabelecida e dominante, seja a norma heterossexual, a norma de branquitude, ou o cânone ocidental e burguês. Alimentando-se no ativismo do ACT $\mathrm{UP}^{1} e$ dos movimentos de luta contra o HIV/AIDS, a teoria queer diferenciou-se, em muitos casos, dos rumos oficiais do movimento LGBT $e$ às suas pautas internacionais de reconhecimento de direitos, considerando esse movimento como pouco subversivo $e$ conformista. Como explicam Paola Bacchetta, Jules Falquet $e$ Norma Alarcón, as teorias queer se diferenciam das posições LGBTs, que passaram "a significar reformismo, no contexto neoliberal" (Bacchetta; Falquet; Alarcón, 2011:8). ${ }^{2}$

Em particular, é nossa intenção apresentar as contribuições mais recentes de téoric@se ativistas queer não branc@s, cujas produções prático-teóricas, mesmo elaboradas nos Estados Unidos ou na Europa, poderiam abrir novas possibilidades de diálogos

\footnotetext{
1 AIDS Coalition to Unleash Power (ACT UP) é uma associação, criada em Nova Iorque, em 1987, para enfrentar a crise da AIDS e fornecer apoio para as pessoas contaminadas pelo vírus.

2 Todas as traduções de textos em línguas estrangeiras (inglês, espanhol $e$ francês) foram feitas pelas autoras deste artigo.
} 
não hierárquicos com o Sul global. Por isso, do ponto de vista metodológico, este texto apresenta uma pesquisa bibliográfica $e$ de revisão de literatura, que pretende disponibilizar um primeiro contato com um campo de produção teórica internacional (prevalentemente escrito em língua inglesa), ainda pouco conhecido no contexto brasileiro. As teorias queers não brancas aparecerão, assim, como uma ampla janela aberta em direção ao mundo contemporâneo, onde a sexualidade não é concebida como separável das principais questóes que atravessam a atualidade, tais como as relações pós/neocoloniais, as tensões étnico-raciais, os novos imperialismos, o terrorismo e os conflitos do mundo neocapitalista.

\title{
Rumo ao Sul
}

Partimos de um texto recentemente publicado pela feminista descolonial Yuderkys Espinosa Miñoso (2015), em que a autora questiona os desafios do trânsito da teoria queer na América Latina: o que uma teoria elaborada nos Estados Unidos e na Europa do Norte vem fazer na América Latina e nos contextos diferentes do Sul global? Tal processo poderia parecer como uma "expansão do eurocentrismo e do seu programa humanístico" (Miñoso, 2015:30). A questão fundamental

\begin{abstract}
(...) diz respeito à genealogia própria da aparição da teoria queer nos Estados Unidos, e como essa teoria chega ao espaço do latino-americano. Como tentei demostrar (...), o pensamento e a política queer chegam a América Latina através do discurso produzido por elites brancas e brancomestiças tanto acadêmicas como ativistas. Não se trata de um dado de menor importância, pois fala sobre o lugar interessado a partir do qual se produzem determinadas miradas e interpretações (Miñoso, 2015:30).
\end{abstract}

$\mathrm{E}$, mais para a frente no texto, a autora questiona a maneira com que essas ideias e práticas teóricas são recebidas e integradas no contexto latino-americano: 
Essa aceitação incondicional da universalização de marcos conceituais e analíticos produzidos dentro da experiência histórica da Europa e dos Estados Unidos resulta problemática enquanto oculta a diferença colonial, impondo conceitualizações e categorias próprias de experiências particulares e dificultando o desenvolvimento de ferramentas e explicações mais adequadas para nossos contextos (Miñoso, 2015:31).

Se, no caso da teoria e da prática feministas, as produções a partir do Sul são extremamente ricas e inovadoras, reivindicando a especificidade da experiência da colonialidade e de outros marcadores sociais para além do gênero, o campo da teoria queer $e$ seu deslocamento epistemológico permaneceriam presos na reprodução das fronteiras entre centro e periferia? No Congresso Desfazendo Gênero II, que ocorreu em Salvador, em 2015, Yuderkys Miñoso apontou para a ausência de corpos negros $e$ indígenas nos espaços da diversidade sexual (e nos espaços mesmo do Congresso) e destacou como a análise do dispositivo da sexualidade, operada por Michel Foucault, permaneceu como um dispositivo da sexualidade branca e burguesa.

De fato, olhando para o campo das produções teóricas queer latino-americanas e, particularmente, brasileiras, constatamos como esse campo permanece, em sua maioria, bastante branco, não tanto e não somente enquanto seus principais porta-vozes sejam brancos, mas porque a temática do cruzamento entre produção de identidades sexuais e de gênero dissidentes, colonialidade e opressão de raça/etnia ou classe apresenta-se como menos desenvolvida.

A maneira com que a abjeção sexo-genérica se expressa em contextos marginais de classe e raça, e a maneira como tais contextos a determinam, é uma pergunta que foi sacrificada em favor da teorização monolítica deste novo sujeito da abjeção de sexo e de gênero (Miñoso, 2015:34). 
Existem, porém, algumas exceções como os textos de Larissa Pelúcio (2012; 2014), Richard Miskolci (2009) a propósito das relações entre teoria queer, estudos subalternos e póscoloniais, assim como o de Pedro Paulo Pereira (2012), que reflete sobre a tradução do queer nos trópicos. Retomando as análises do artista visual e ativista chileno, Felipe Rivas San Martín, intérprete de um vasto debate latino-americano que aponta para o caráter inadequado do termo cuir/queer em contextos hispanofónos $e$ lusófonos, Larissa Pelúcio considera que também

\begin{abstract}
em português "queer" nada quer dizer ao senso comum. Quando pronunciado em ambiente acadêmico não fere o ouvido de ninguém, ao contrário, soa suave (cuier), quase um afago, nunca uma ofensa. Não há rubores nas faces nem vozes embargadas quando em um congresso científico lemos, escrevemos ou pronunciamos queer. Assim, o desconforto que o termo causa em países de língua inglesa se dissolve aqui na maciez das vogais que nós brasileiros insistimos em colocar por toda parte. De maneira que a intenção inaugural desta vertente teórica norte-americana, de se apropriar de um termo desqualificador para politizálo, perdeu-se no Brasil (Pelúcio, 2014:4).
\end{abstract}

O trânsito da teoria queer para o Brasil e toda a América do Sul, que Larissa Pelúcio denomina com ironia o "cu do mundo", testemunha uma "geopolítica do conhecimento" (Pelúcio, 2014:10) que separa um suposto centro de suas periferias, um Norte produtor de ideias e um Sul simplesmente receptor. Continua Pelúcio,

se o mundo tem cu é porque tem também uma cabeça. Uma cabeça pensante, que fica acima, ao norte, como convém às cabeças. Essa metáfora morfológica desenha uma ordem política que assinala onde se produz conhecimento $e$ onde se produz os espaços de experimentação daquelas teorias (Pelúcio, 2014:10). 
A preocupação de descolonizar as sexualidades dissidentes atravessa também a coletânea Discursos fora da ordem, organizada por Richard Miskolci e Larissa Pelúcio, em 2012. A intenção desse trabalho é "apresentar uma amostra cartográfica dos deslocamentos, das reivindicações e das demandas por reconhecimento que caracterizam o cenário contemporâneo" (Miskolci; Pelúcio, 2012:9), articulando o contexto local com o global e discutindo a intersecção de diferentes marcadores sociais. A coletânea mobiliza, além da teoria queer, os estudos feministas, $e$ os estudos pós-coloniais e subalternos, enquanto posicionamentos teóricos que se opõem ao modelo epistemológico hegemônico do pensamento ocidental. Os saberes subalternos são, assim, mobilizados como aqueles
que partilham de um lugar epistêmico questionador das teorias eurocêntricas que, sob alegado universalismo, privilegiam uma forma de conhecer que toma o Ocidente, a branquitude, o masculino $e$ a heterossexualidade como a medida do humano (Miskolci; Pelúcio, 2012:10).

No conjunto das dominações aqui mencionadas, aparece a heteronormatividade ou heterossexualidade normativa. Surge, dessa forma, o questionamento sobre a maneira com que alguns comportamentos, práticas ou modos de vida, reivindicados por gays e lésbicas, se tornam normativos e terminam reproduzindo padrões sociais acriticamente associados ao cânone burguês $e$ à branquitude. É a questão abordada por Judith Jack Halberstam no texto "Repensando o sexo e o gênero", publicado, em tradução, nessa coletânea. Halberstam sugere que se abandonem "certas narrativas heroicas sobre sexo e dissidentes sexuais que alocam homossexuais como sendo sempre, e em toda parte, progressistas, oprimid@s e enfrentando o poder" (Halberstam, 2012:126). Ou seja, contar a história das minorias sexuais e de seu enfrentamento ao poder das normas sociais estabelecidas implica, ao mesmo tempo, enfrentar outras histórias, como a da assimilação à sociedade capitalista neoliberal e seus padrões, 
como a dos "homossexuais burgueses, das famílias e dos casais homossexuais, dos homossexuais decentes e cristãos, das hierarquias raciais e dos homossexuais brancos" (Halberstam, 2012:127). ${ }^{3}$

O texto de Larissa Pelúcio, "Subalterno quem, cara pálida? Apontamentos às margens sobre pós-colonialismos, feminismos $e$ estudos queer", contesta as fronteiras fixas entre centro e periferia $e$, sobretudo, as relações hegemônicas que ali se cristalizam. Por isso, segundo a autora, no campo da teoria queer, "temos que construir $e$ afinar nossas próprias ferramentas conceituais $e$ teóricas, justamente para pensar essa realidade particular" (Pelúcio, 2012:413) que são os contextos latino-americano e brasileiro, nos quais sexualidades, desejos e regimes eróticos são marcados pelas relações coloniais e por múltiplas formas de exploração e de subalternização, pela racialização da sexualidade e pela sexualização das relações raciais. Escreve, com lucidez, Larissa Pelúcio:

Nossa drag, por exemplo, não é a mesma do capítulo 3 do Problemas de Gênero de Judith Butler (2003), nem temos exatamente as drag kings das oficinas de montaria de Beatriz Preciado, ou sequer, podemos falar de uma história da homossexualidade do mesmo modo de David M. Halperin, ou da Aids como o fez Michel Warner. Nosso armário não tem o mesmo "formato" daquele discutido por Eve K. Sedgwick. Cito aqui o quinteto fantástico do queer. Ainda que entre nós alguns nomes sejam mais familiares que outros, foi essa a bibliografia que chegou com mais

3 Agradecemos ao estudante Mailson Barreto que, em uma discussão no Grupo de Pesquisa FEMPOS/UNILAB, chamou nossa atenção sobre o uso da noção de homonormatividade no contexto brasileiro. A pesquisa em site e blogs frequentados por homens gays mostra que esse termo é frequentemente objeto de crítica e que a maioria dos participantes rejeita a ideia de uma norma homossexual. É exemplo disso, o texto de Gilmaro Nogueira, publicado no blog ibahia (cfr. http://www.ibahia.com/a/blogs/sexualidade/2013/04/01/ahomonormatividade-nao-existe/). 
força até nós a partir do território queer euro-americano, (Pelúcio, 2012:413).

Ou seja, essa foi a bibliografia consagrada da teoria queer norte-americana e europeia que conseguiu se impor, de forma mais recorrente, no contexto brasileiro; uma bibliografia que, com Paola Bacchetta, Jules Falquet e Norma Alarcón, poderíamos definir como "teorias queer brancas" (Bacchetta; Falquet; Alarcón: 2011:7), predominantemente centradas na discussão sobre gênero e sexualidades.

Um número da revista Periodicus, publicado em 2015, por ocasião da vinda de Judith Butler a Salvador, nos parece um exemplo dessa situação. Entre os diferentes textos que apresentam leituras brasileiras do pensamento de Butler e que discutem um amplo painel temático (corporeidade, gênero, poder, performance, performatividade, subjetividade...), só o último Carta de uma ex-mulata a Judith Butler, escrito pela professora da UFRB, Ângela Figueiredo, tenta articular os estudos de gênero e sexualidades com aqueles que a autora chama de "estudos das hierarquias raciais" (Figueiredo, 2015:153). O texto analisa as diferenças entre os contextos sócio-históricos norte-americano e brasileiro, em matéria de questões raciais, abrindo o diálogo com a teoria queer e com o significado que ela assume nesses diferentes contextos. Escrito em forma autobiográfica, o texto apresenta as ambiguidades da sociedade brasileira e propõe as políticas de identidade como necessárias para a politização das pautas de grupos tradicionalmente marginalizados: "Quer dizer, para os sujeitos não brancos, coloniais, do ponto de vista das lutas políticas por acesso a direitos, não há motivo para a diluição das identidades" (Figueiredo, 2015:157).

No campo dos estudos indígenas brasileiros, sinalizamos os trabalhos do antropólogo Estevão Fernandes (2015, 2017a e 2017b) sobre as relações homossexuais vivenciadas por indígenas. Estevão Fernandes compara a situação brasileira a dos nativos norte-americanos e canadenses, destacando, em particular, as contribuições da teoria Queer/Two-Spirit, que o autor entende 
como uma abordagem descolonial da dissidência sexual (Fernandes, 2017a). Nos contextos estadunidense e do Canadá, as perspectivas Queer/Two Spirit referem-se às identidades indígenas LGBTIQ. O termo visa, assim, a contestar a heteronormatividade enxergada como um projeto colonial. Escreve, a esse propósito, Fernandes:

\begin{abstract}
assumir-se como dois espíritos não apenas foca no papel espiritual da pessoa - e não em suas práticas sexuais - como também significa uma crítica ao processo de colonização: parte considerável dos escritos produzidos por autores $e$ ativistas two-spirit se assenta na análise e crítica aos processos de colonização que os estigmatizaram. Assim, o movimento organizou-se a partir de uma crítica ao aparato colonial moldada desde uma identidade pan-indígena $e$ amparada por um discurso espiritual (Fernandes, 2017a:100).
\end{abstract}

Nesse sentido, as contribuições de Fernandes dialogam com as da teoria Queer of Color, ao mostrar as heranças coloniais presentes nos discursos sobre a sexualidade, mas também ao apontar para o fato de que a oposição à homofobia, à heteronormatividade, e a afirmação de sua dissidência sexual atuam, ao mesmo tempo, como uma crítica ao racismo e ao "sistema colonial" (Fernandes, 2017a:105).

Outra contribuição que, no contexto brasileiro, se aproxima mais dos debates Queer of colour é o texto de Bruna Irineu, "Homonacionalismo e cidadania LGBT em tempos de neoliberalismo: dilemas e impasses às lutas por direitos sexuais no Brasil", que data de 2014. Ao analisar as lutas em prol dos direitos sexuais $e$ as demandas por cidadania por parte das populações LGBT, a autora introduz uma crítica à noção de homonacionalismo, no sentido de Jasbir Puar, e às lógicas neoliberais que dominam a comunidade LGBT e muitas das suas atuais pautas. Aparece, nesse artigo, o questionamento sobre a existência de um homonacionalismo à brasileira, no qual os direitos sexuais se tornam moeda de troca para encobertar outras formas de opressão, socioeconômicas ou raciais. 
É preciso questionar: a que custo pretendemos negociar nossa "cidadania de consolação"? Vamos lavar de rosa o sangue de grupos étnicos, imigrantes e trabalhadores em condição de escravidão que estes governos nacionalistas têm derramado? Ou iremos construir uma alternativa anticapitalista que rompa com o homonacionalismo? (Irineu, 2014:175).

Para responder de maneira exaustiva a essas instigantes questões, porém, seria necessário chamar em causa, de forma mais ampla, o corpus teórico da crítica Queer of Colour.

Diante desse cenário e das dificuldades de traduzir a teoria queer norte-americana para os contextos do Sul, em particular América Latina e Brasil, sem reproduzir formas hegemônicas e de colonialidade do saber, seria necessário destacar a importância do campo de pesquisa chamado Queer of Colour Critique. Numa entrevista publicada pela revista CULT, Marie-Hélène/Sam Bourcier reflete sobre a questão da tradução do queer (do termo e da teoria) nos contextos locais externos ao chamado Norte Global. Para Bourcier, seria então importante inventar "um outro termo, que não o queer, algo menos imperialista" (Bourcier, 2015:14). E continua: "é preciso se desvencilhar da teoria branca queer da primeira onda, e para isso, há fontes importantes na crítica das QOC (Queer of Colour), inclusive nos Estados Unidos. Foi o que Gloria Anzaldúa começou" (Bourcier, 2015:15). Só dessa forma será possível, continua Bourcier, "descolonizar o queer, e (...) aprender lições com o racismo epistêmico europeu, que nos formou, mas que ainda fascina a América Latina" (Bourcier, 2015:15).

Precisamos aqui constatar que as referências da crítica Queer of Colour estão ainda pouco traduzidas e conhecidas no Brasil e em outros contextos latino-americanos, e que só rara $e$ perifericamente, elas são trazidas como interlocutoras das 
produções queer latino-americanas e brasileiras. ${ }^{4}$ No caso da teoria feminista, a mediação dos textos de expoentes do feminismo pós-colonial, do feminismo transnacional $e$ particularmente do Black Feminism norte-americano foi significativa para introduzir e consolidar a perspectiva interseccional no campo dos estudos feministas e de gênero, no Brasil e em grande parte da América Latina. Pensamos que, de maneira análoga, o confronto com o campo prático-teórico QOC possa ser extremamente frutífero para a criação $e \quad o$ desenvolvimento da teoria queer nos contextos do Sul. Mas, antes de entrar nessa questão, devemos apresentar mais em detalhe esse campo de produção teórica e militante.

${ }^{4}$ Existem, porém, alguns textos de autoras Queer of Colour que circulam em português: lembramos a tradução de um texto da teórica queer de origem indiana, Jasbir Puar, pela Revista Lusófona de Estudos Culturais. Este texto, publicado no final de 2015, é uma importante contribuição dessa autora sobre a noção de homonacionalismo e sobre a construção de uma retórica da modernidade e do progresso linear no campo dos direitos liberais de gays $e$ lésbicas. Jasbir Puar faz uma crítica cerrada dessa retórica e de suas consequências que racializam e excluem determinados grupos e populações da esfera de uma plena cidadania. Também destacamos a recente tradução, em 2014, pela Revista Meritum, de Belo Horizonte, de um texto de Jin Haritaworn sobre os crimes de ódio e a criminalização das populações de origens árabe $e$ muçulmana, em muitos países do Norte da Europa e nos Estados Unidos. Em 2013, um primeiro texto de Jasbir Puar foi publicado pela Revista Meritum, "Prefiro ser um ciborgue a ser uma deusa': interseccionalidade, agenciamento". Esse texto discute criticamente a ideia de interseccionalidade, propondo uma reformulação dessa categoria à luz da noção deleuzeana de agencement. Há ainda um texto, de alguns anos antes (2009), de Paola Bacchetta, publicado em uma coletânea da Editora Mulheres, de Florianópolis. O texto, intitulado "Coformações/co-produções: considerações sobre poder, sujeitos subalternos, movimentos sociais e resistência", discute as posições prático-teóricas e as estratégias de militância de movimentos de mulheres lésbicas racializadas e subalternizadas em função de sua religião, classe ou condição colonial, atuantes na França, na Índia e nos Estados Unidos. Assinalamos também a importância da vinda de Jasbir Puar para o Congresso Internacional Desfazendo Gênero III, em Campina Grande/Paraíba, em outubro de 2017, como um exemplo de um novo interesse, no contexto brasileiro, pela crítica Queer of Colour. 


\section{Contribuições QOC}

O trecho da entrevista com Bourcier, que acabamos de citar, nos permite colocar ênfase na importância não periférica das questões étnico-raciais e de classe para a crítica queer, segundo a qual o enfrentamento às normas sexuais, sociais e corporais pressupõe sempre uma leitura interseccional da dominação. Mais radicalmente, precisamos apontar, como o próprio Sam Bourcier sugere, para uma genealogia não branca da teoria queer. Ou seja, antes mesmo da chamada primeira onda queer (Butler/de Lauretis), foi a chicana Gloria Anzaldúa quem utilizou pela primeira vez num texto teórico, o termo queer, como estratégia para desestabilizar as fronteiras sexuais, de gênero, mas também raciais, culturais, linguísticas e de classe (Anzaldúa, 2012). Paola Bacchetta, Jules Falquet e Norma Alarcón destacaram como, apesar da gênese do termo queer no campo acadêmico ter sido atribuída a Teresa de Lauretis, "uma outra genealogia" (Bacchetta; Falquet; Alarcón, 2011:3) é possível, a partir da obra de Anzaldúa que, no texto Borderlands/La Fronteira; The New Mestiza, autodenominou-se como queer, introduzindo pela primeira vez esse termo na academia norte-americana. As autoras se referem à palestra de Randy Conner, pronunciada em 2009, durante a Conferência El Mundo Zurdo - An International Conference on the Life and Work of Gloria Anzaldúa - que apontou essa outra genealogia do queer a partir da obra da feminista chicana. ${ }^{5}$

5 Não podemos, porém, esquecer que Teresa de Lauretis contribuiu, por sua vez, para valorizar as contribuições de gays e, particularmente, de lésbicas não branc@s para a gênese da teoria queer. Ela aponta a necessidade de "levar em conta a raça e as diferenças de classe, cultura étnica, as diferenças de geração, de situação geográfica e sociopolítica" (De Lauretis, 2007:106) . A autora afirma que "uma das questões mais problemáticas que o campo emergente dos estudos gays e lésbicos coloca, concerne as construções discursivas sobre as relações entre raça, identidade e subjetividade nas práticas das homossexualidades e as representações do desejo pelo mesmo sexo" (De Lauretis, 1990/2007:106). De Lauretis cita a importância dos escritos de lésbicas e gays de cor, das feministas negras lésbicas (Barbara Smith, Gloria T. Hull, Patricia Bell Scott, Audre Lorde) e 
É essa a encruzilhada da existência que o queer representa, enquanto experiência de um corpo simultaneamente marcado enquanto mulher, chicana, não branca, lésbica, de língua e cultura hispânicas no contexto dos Estados Unidos.

Como mestiza, eu não tenho país, minha terra natal me despejou; no entanto, todos os países são meus porque eu sou a irmã ou a amante em potencial de todas as mulheres. (Como uma lésbica não tenho raça, meu próprio povo me rejeita; mas sou de todas as raças porque a queer em mim existe em todas as raças). Sou sem cultura porque, como uma feminista, desafio as crenças culturais/religiosas coletivas de origem masculina dos indo-hispânicos e anglos; entretanto, tenho cultura porque estou participando da criação de uma outra cultura, uma nova história para explicar o mundo e a nossa participação nele, um novo sistema de valores com imagens e símbolos que nos conectam um/a ao/à outro/a e ao planeta. Soy un amasamiento, sou um ato de juntar e unir que não apenas produz uma criatura tanto da luz como da escuridão, mas também uma criatura que questiona as definições de luz $e$ de escuro e dá-lhes novos significados (Anzaldúa, 2005:707708).

Podemos, assim, afirmar que, desde o início, a teoria queer e suas práticas políticas estão engajadas na reflexão e na ação contra "o demônio de muitas cabeças da opressão" (Anzaldúa; Moraga, 1981:195).

A partir dessa genealogia diferente - subalterna e não branca - do queer, seria talvez possível abrir novos caminhos para o desenvolvimento dessa teoria, facilitando suas traduções e deslocamentos nos contextos do Sul. Ou seja, a valorização dessa genealogia não branca da teoria queer poderia facilitar o diálogo e a construção de novas pontes e formas de solidariedade entre o que a feminista chicana pós-colonial Chela Sandoval chama de

das chicanas (Gloria Anzaldúa, Cherrie Moraga, Emma Perez, Carla Trujillo), cujas contribuições foram fundamentais na construção da nascente teoria queer. 
"terceiro-mundo estadunidense" (Sandoval, 2011), e que nós gostamos mais de chamar o Sul do Norte, e os inúmeros contextos locais do Sul do Sul?

Precisamos então dar maior visibilidade a essas fontes não brancas da teoria queer e sondar mais, em profundidade, essas outras versões dessa teoria, que se unem embaixo do guardachuva da QOC e da teoria queer descolonial. As teorias queer não brancas estão, hoje, se desenvolvendo nos Estados Unidos e na Europa, sob o impulso de militantes e acadêmic@s queer afrodescendentes e oriund@s de contextos pós/neocoloniais. A teoria Queer of Colour constitui, no contexto atual, uma voz radical que se opõe ao conformismo de muitos grupos LGBT, na maioria dos países centrais. Com as palavras do sociólogo afrodescendente, Roderick A. Ferguson, o autor de Aberrations in Black, definimos as teorias Queer of Colour como uma

interrogação das formações sociais em termos de intersecções de raça, gênero, sexualidade e classe, com o interesse particular em destacar como essas formações correspondem ou divergem de ideais e práticas nacionalistas. A análise Queer of Colour é uma empresa heterogênea que deriva do feminismo das mulheres nãobrancas, de análises materialistas, da teoria pósestruturalista e da crítica queer (Ferguson, 2003:147).

${ }^{6}$ A expressão terceiro-mundo estadunidense é usada pela feminista pós-colonial e chicana Chela Sandoval e se tornou uma expressão comum entre as feministas não brancas e @s Queers of Colour. A expressão denota os laços de solidariedade e a consciência histórica comum que une "diferentes tipos de comunidades internamente colonizadas" (Sandoval, 2011:1) e racializadas, oriundas de diásporas e imigrações antigas e mais recentes, assim como os próprios nativos americanos. Paola Bacchetta, Jules Falquet e Norma Alarcón destacam que, apesar de ser um grupo heterogêneo e mutável, o chamado terceiro mundo estadunidense "inclui principalmente pessoas de classe popular" (Bacchetta; Falquet; Alarcón, 2011:4). Essas autoras dedicam-se, em particular, às produções prático-teóricas de cunho feminista e queer, originadas no contexto do terceiro-mundo estadunidense. Essa categoria encarna aquilo que podemos chamar de Sul do Norte, um Sul simbólico e metafórico cujas fronteiras ultrapassam as localizações geográficas do Sul. 
Salientamos a importância dessas perspectivas, que consideram as questões de gênero $e$ sexualidade como inseparáveis da história pós/neocolonial do ocidente, englobando as experiências da escravidão, do racismo, da diáspora e dos fenômenos de imigração e dos novos imperialismos. Nas palavras de Paola Bacchetta, Jules Falquet e Norma Alarcón, as

\begin{abstract}
teorias queer of Color estadunidenses podem ser definidas como teorias queer que abordam, sem separá-los, o gênero, as sexualidades, o racismo, a colonialidade, o genocídio, o escravagismo, o pós-escravagismo e a exploração de classe (...). As críticas queer of Color são produzidas principalmente, mas não exclusivamente, por pessoas queer não-brancas (Bacchetta; Falquet; Alarcón, 2005:2).
\end{abstract}

Reivindicando a radicalidade da tradição do Combahee River Collective e das autoras de This Bridge called my Back, a teoria QOC afirma as raízes comuns das opressões, $e$ particularmente, a interdependência do racismo, do sexismo e do heterossexismo e, assim, a importância de construir estratégias simultâneas de lutas, enfrentando a complexidade dos regimes de opressão. Afirma o Manifesto QOC de 1995,

@s Queers of Colour são muitas vezes marginalizad@s nos grupos que são já marginalizad@s. Somos obrigad@s a enfrentar o racismo e a homofobia na sociedade como um todo, como a enfrentar o racismo na comunidade queer, $e$ a homofobia nas comunidades de cor (...). Afirmamos a unidade com todas as organizações engajadas na luta contra o racismo e a homofobia. E esperamos o dia em que a sociedade será verdadeiramente e plenamente igualitária (Manifesto, 1995).

É importante considerar que o guarda-chuva da teoria Queer of Colour perpassa as identidades étnico-raciais de quem nele se reconhece, e se define, mais precisamente, como uma opção política e teórica, que consiste no engajamento a uma 
leitura complexa e interseccional do gênero e das sexualidades, articulando-os com a crítica aos fenômenos da expansão capitalista neoliberal, dos novos imperialismos e da produção de hierarquias e privilégios em termos de raça, nacionalidade e classe no seio das comunidades LGBT, aos níveis nacional e global. Nesse sentido, as teorias QOC se diferenciam daquelas que, por oposição teórica, chamamos de "teorias queer brancas", que colocam em primeiro lugar a figura $e$ as reivindicações de um "sujeito dominante do ponto de vista da raça, da colonialidade e da classe, ou seja, um sujeito branco de classe média" (Bacchetta; Falquet; Alarcón, 2011:3). Destacamos, assim, o lugar nãoidentitário desse campo prático-teórico que não se define a partir de uma identidade fixa, do posicionamento étnico-social de quem pesquisa, mas sim a partir de um "lugar epistêmico questionador" (Miskolci; Pelúcio, 2012:10) da homonormatividade eurocêntrica e neoliberal.

Consideramos importante destacar que a plataforma QOC reúne um vasto arco de autor@s, escritor@s, teóric@s, academic@s, artistase militantes, oriund@s dos diferentes grupos marginalizad@s e racializad@s. Ela inclui a Black Queer Theory, mas também as produções de autor@s chican@s e latin@s, árabes, asiatic@s e indígenas que questionam o modelo homonormativo que impõe "uma agenda política restritiva (...), uma história teleológica e uma concepção ocidental da sexualidade e da modernidade" (Cervulle; Rees-Roberts, 2010:41). ${ }^{7}$ Mencionamos, aqui, alguns textos de referência nessa área: a

7 A noção de homonormatividade é ainda uma noção polêmica nos movimentos e nas comunidades LGBT. Ela é, porém, usada por muit@s autor@s que se identificam como Queer of Colour para questionar a despolitização e privatização das vidas de gays e lésbicas nos países ocidentais. Num texto recentemente traduzido para o português, Jin Haritaworn cita Lisa Duggan que define a homonormatividade como uma "nova política sexual neoliberal [...] que não contesta as premissas e instituições heteronormativas dominantes, mas as respeita $e$ as apoia, ao mesmo tempo que promete a possibilidade de um eleitorado gay desmobilizado e uma cultura gay privatizada, ancorada na domesticidade, no consumo e na privacidade" (Duggan, 2003, apud Haritaworn, 2014:212). 
antologia Black Queer Theory, editada por Patrick Johnson e Mae Henderson (2005), que une contribuições de queers afrodescendentes, reivindicando a intersecção entre estudos negros e estudos queers; a coletânea Queer Indigenous Studies. Critical Interventions in Theory, Politics and Literature, coordenada pelo teórico e poeta Cherokee, Qwo-Li Driskill \& outr@s; o texto da alemã diaspórica, Fatima El Tayeb, European Others. Queering Ethnicity in Postnational Europe, que analisa a condição das comunidades racializadas nos países europeus (Alemanha, França e Holanda, em particular) e critica os nacionalismos europeus do ponto de vista da Teoria Queer of Colour e das subculturas queers diaspóricas. Fatima El Tayeb usa, nesse livro, os termos queer e queerness não como simples referentes a identidades sexuais:

Um dos mais interessantes aspectos da crítica Queer of Colour - afirma a autora - é sua recuperação do queer como um termo que não é simplesmente sinônimo de homossexual, mas que se refere a processos de construção de comportamentos $e$ de grupos normativos $e$ não normativos. A interação de raça, classe e gênero na construção das sexualidades desviantes cria grupos $e$ hierarquias mais complexos que a simples oposição dicotômica entre homossexual e heterossexual; queer pode então ser usado em oposição às formações homonormativas (El Tayeb, 2011:XXXV).

Nessa linha vão, também, os textos críticos ao homonacionalismo e à islamofobia que, nos últimos tempos, caracteriza muitos movimentos LGBT no Ocidente: entre esses textos, lembramos Terroristic Assemblages. Homonacionalism in Queer Times, da teórica indiana Jasbir Puar (2007), que aponta para o crescente fenômeno do excepcionalismo sexual dos EUA e do Ocidente, também chamado de nacionalismo homossexual. Esse nacionalismo sexual, segundo Puar, é, na verdade, uma maneira de encobrir atitudes racistas, imperialistas e neocoloniais, difundidas nos países ocidentais, especialmente após o 11 de 
setembro 2001. No livro Desiring Arabs, o palestino Joseph Massad retoma as teses de Edward Said e destaca o laço que, desde a época colonial, vincula a sexualização do imaginário orientalista à orientalização racializante da sexualidade do Outro não ocidental. Nessa direção, Massad contesta as estratégias elaboradas pela "Internacional Gay", um conjunto de organizações e ONGs LGBTQ internacionais, mas sediadas nos países do Norte que, seguindo uma lógica missionária, impõem suas agendas e sua compreensão da homossexualidade aos países do Sul, julgados como intrinsecamente homofóbicos e patriarcais. Reportamo-nos a um trecho do livro de Massad, em que o autor expõe sua crítica ao ativismo da Internacional Gay:

Minha argumentação é que o discurso próprio da Internacional Gay, que ao mesmo tempo produz os homossexuais, gays e lésbicas, onde eles não existem, reprime os desejos do mesmo sexo $e$ as práticas que rejeitam serem assimiladas na sua epistemologia sexual. Mostrarei que esse discurso assume, de maneira prédiscursiva, que os homossexuais, gays e lésbicas, são uma categoria universal que existe em qualquer lugar no mundo $e$, baseada nesse axioma pré-discursivo, a Internacional Gay se coloca a missão de defendê-los, pedindo que seus direitos enquanto homossexuais sejam garantidos, onde são negados, e respeitados, onde são violados. Ao fazer isso, porém, a Internacional Gay (...) produz um efeito que está longe de ser liberatório (Massad, 2007:163).

O paradoxo para o qual apontam as reflexões de Massad consiste em revelar que a intervenção das associações da Internacional Gay estaria longe de produzir os efeitos esperados de libertação das populações LGBT, levando, ao contrário, à radicalização das perseguições contra esses grupos (particularmente nas comunidades rurais ou mais desfavorecidas), que passam a serem identificados como os porta-vozes presumidos dos interesses das potências ocidentais neocolonizadoras. Essas inquietações estão presentes em várias 
das contribuições de autor@s Queer of Color como, por exemplo, na coletânea editada, em 2016, por Sandeep Bakshi, Suhraiya Jivraj e Silvia Posocco e intitulada Decolonizing sexualities. Transnational perspectives, critical interventions. Na introdução à coletânea, @s autor@s chamam de queerness descolonial aquela que se preocupa com questionar as epistemologias neocoloniais que atravessam o campo das sexualidades, através da retórica hegemônica perpetuada em muitas das comunidades LGBT dos países centrais. Tal retórica reivindica a suposta superioridade da modernidade ocidental nas questóes sexuais e de gênero. Assim, para@s autor@s,

um exame do impacto do apagamento de diversas formas de ser se torna crucial nos contextos queer, pois o Ocidente é construído como o campeão progressista das subculturas queer ao nível global. O racismo cultural nos circuitos queer funciona junto ao imaginário cultural do Sul Global como um lugar necessariamente homofóbico e produz códigos hegemônicos de colonialidade, que obtém apoio para empreendimentos neocoloniais e neoimperiais, legitimando o Norte global como o único garante de direitos humanos para todas as pessoas, incluindo mulheres e sujeitos queer (Bakshi; Jivraj; Posocco, 2016:1-2).

A centralidade dessa retórica na epistemologia euroamericana da sexualidade não faz senão reforçar o nexo intrínseco entre colonialidade e modernidade. Na esteira de Walter Mignolo, autor do prefácio à coletânea Decolonizing sexualities, Bakshi, Jivraj e Posocco escrevem que a colonialidade

é constitutiva e não derivada da modernidade. Por esta razão, escrevemos modernidade/colonialidade (...): "não tem modernidade sem colonialidade". Neste aspecto, a descolonialidade constitui a separação dos discursos sobre o conhecimento que o pensamento euro-americanocêntrico faz proliferar (Bakshi, Jivraj; Posocco, 2016:4). 
Do ponto de vista Queer of color, tratar-se-ia de denunciar $e$ criticar, na figura do gay branco e de classe média, a principal referência das políticas LGBT mainstream do Ocidente. Direitos como o casamento gay, a homoparentalidade ou a visibilidade são, sem dúvida, direitos muito importantes, mas é preciso ter em conta a multiplicidade interligada das relações de poder que existem, também, no seio da própria comunidade LGBT. Um trecho de Fatima El-Tayeb enuncia, com lucidez, esse ponto:

O ativismo LGBT corrente tem muito a dizer sobre o casamento como um direito humano, mas praticamente nada a dizer sobre direitos humanos, como o direito à comida, ao trabalho, a um salário mínimo ou sobre o direito de ser protegido da detenção arbitrária. Ganhos reais em um setor estritamente definido, como o casamento entre pessoas do mesmo sexo, são tomados como uma prova da narrativa do progresso constante $e$ do engajamento humanitário no Ocidente e, particularmente, na Europa, que é considerada como a mais avançada em relação aos direitos das mulheres e dos gays. Porém, estes ganhos não estão enquadrados como parte de um pulo maior em direção à igualdade e à justiça social, nem tem um reconhecimento da velha e nova violência que acompanham o multiculturalismo neoliberal, oferecendo inclusão a alguns dos grupos anteriormente excluídos, desde que se adaptem ao modelo do cidadão consumidor (El-Tayeb, 2016:154).

Dessa forma, conclui a autora, a verdadeira libertação só pode ocorrer quando todos esses sistemas de opressão forem transformados e alterados, de forma que "é impossível desmantelar a homofobia sem desmantelar o racismo, que, por sua vez, não pode ser desmantelado sem desmantelar o sexismo, $e$ assim por diante" (El-Tayeb, 2016:163).

Nessa direção, cabe também mencionar os trabalhos de Jin Haritaworn (2008 e 2012), alemão originário do Sul-Leste asiático, que chama a atenção sobre a cumplicidade de gays brancos $e$ ocidentais com a guerra ao terrorismo e com a "globalização do 
racismo contra os muçulmanos" (Haritaworn, 2008:2). O autor destaca como foi, a partir dessa cumplicidade com o imperialismo ocidental e com um certo ideal hegemônico de masculinidade, que muitos gays conquistaram seu acesso à esfera dos direitos $e$ da cidadania, deixando às margens os corpos não policiados pelas "múltiplas normatividades acerca do heterossexismo, da branquitude e dos padrões de classe média, entre os quais a branquitude foi privilegiada enquanto marca do essencialismo $e$ das identidades políticas gays" (Haritaworn, 2008:6).

O livro de Maxime Cervulle e Nick Lees-Roberts, publicado em 2010, com o título Homo Exoticus. Race, classe et critique queer aborda também essas questões. Esse texto apresenta o contexto LGBT francês durante a primeira década do século XXI, suas reivindicações por direitos e seu conformismo burguês, questionando abertamente a homonormatividade, assim como, a retórica dos discursos que opõem as lutas das minorias sexuais $e$ das minorias etnicizadas. Nesse cenário, as análises QOC vêm contestar a visão eurocêntrica da modernidade sexual, na qual as sexualidades gays e lésbicas se tornam o principal fator de representação da modernidade e da democracia. "A epistemologia sexual ocidental é instrumentalizada para significar a modernidade, rejeitando consequentemente outros tipos de racionalização do domínio do sexual na pré-modernidade" (Cervulle; Rees-Roberts, 2010:40). De forma análoga, recuperamos as teses de Jasbir Puar, Paola Bacchetta e Jin Haritaworn que introduzem a expressão homotransnacionalismo para indicar as múltiplas cumplicidades das nações ocidentais $e$ de suas populações LGBT em alimentar a ideologia homonacionalista, islamofóbica, assim como, a racialização $e$ a nacionalização das sexualidades (Haritaworn; Bacchetta, 2015; Bacchetta, 2015). Dessa forma, as autoras definem o homotransnacionalismo como sendo

a produção e a circulação, especificamente transnacional, dos discursos neocoloniais, orientalistas, sexistas $e$ queerfóbicos, que identificam as mulheres $e$ as pessoas queer muçulmanas como vítimas. Tais discursos circulam através do Norte Global, mas podem ser também 
encontrados em outros lugares (Bacchetta; Haritaworn, 2015:191).

Da Alemanha à França, da Holanda aos países da Europa do Norte e aos Estados Unidos, nas últimas décadas, fazem sua aparição as figuras estereotipadas do muçulmano homofóbico, dos bairros periféricos racializados, habitados por homens supostamente violentos e patriarcais, oriundos do Sul Global. Assim, essas narrativas do medo e da segurança, perpetuadas pelos movimentos LGBT brancos dos países centrais, "oferecem para um pequeno grupo de sujeitos homonormativos, nacionais $e$ assimilados, a possibilidade, ausente no passado, de performar respeitabilidade e pertencimento" (Haritaworn; Bacchetta, 2015:187).

Reconhecer a existência da homonormatividade e de subjetividades homonormativas significa, segundo Roderick Ferguson, reconhecer "a entrada da homossexualidade na esfera da supremacia branca" (Ferguson, 2005:65). No contexto dos nacionalismos de muitos países centrais e da lógica do capitalismo neoliberal, os grupos economica e racialmente vulneráveis encontram-se mais facilmente expostos a processos de exclusão, de patologização e de criminalização, e são rejeitados às margens da ordem social. Dessa forma, "o imigrante, o pobre e o sujeito não branco sofrem sob os aparatos estatais - aparatos que os tornam antíteses culturais de uma ordem social estável e saudável" (Ferguson, 2005:65). A entrada de gays e lésbicas na esfera da normatividade burguesa e do conforto da sociedade de consumo acaba rejeitando outras vidas e outros corpos, julgados menos viáveis e aceitáveis aos olhos da sociedade conformista e branca do capitalismo liberal.

Em outras palavras, o apelo para uma normatividade de gênero e sexual por parte de gays e lésbicas, neste momento, opera, de forma inevitável, como um modo de identificação do Estado que promove a exclusão racial. Os direitos gays se tornaram um sitio de exclusão racial e de privilégio, definido pelo direito ao casamento, pela proteção 
contra os crimes de ódio e pela inclusão militar (Ferguson, 2005:61).

Nessa direção, vai também a coletânea curada por David Eng, Judith Halberstam e José Esteban Muñoz, What is Queer about Queer Studies Now?, que se coloca sob o guarda-chuva QOC, ao denunciar a recuperação/assimilação das identidades gays e lésbicas pelo mercado neoliberal. Esse texto testemunha as solidariedades entre teóricos e ativistas queers branc@s e não branc@s, sendo David Eng originário do leste asiático, Judith Halberstam norte-americana branca e Estebán Muñoz de origem cubana.8Escrevem@s autor@s, na introdução:

Muita teoria queer hoje dá a impressão de uma metanarrativa sobre as questões domésticas de homossexuais homens e brancos. Com certeza, os estudos queer prometem algo mais do que uma história do homem gay branco, uma sociologia dos sex-clubs gays, uma antropologia do turismo gay ou uma pesquisa sobre a estética gay (Eng; Halberstam; Muñoz, 2005:12).

Em particular, o texto de Judith Halberstam, que integra essa coletânea, "Shame and White Gay Masculinity", aponta para a necessidade de posicionar os estudos queer na direção de um novo campo de pesquisa que transcenda a hegemonia masculina, burguesa e branca, à qual uma boa parte da teoria queer tem recentemente se subordinado. Para renovar os estudos queer na época do liberalismo gay, é preciso

deixar de lado as políticas identitárias de homens gays brancos e apreender das críticas radicais oferecidas por uma jovem geração de estudios@s queer intelectualmente inspirad@s no feminismo, nos estudos étnicos, mais do que nos estudos queer brancos (Halberstam, 2005).

8 Cabe aqui lembrar que no contexto norte-americano, as populações de origem latina ou asiática são classificadas, na maioria dos casos, como não brancas $e$ como racializadas. 


\section{A chapa Queer African}

A questão que queremos levantar com este texto é se, partindo d@s QOC como novo disparador da teoria queer, não seria possível traçar uma história diferente das circulações e dos deslocamentos dessa teoria, e permitir novas formas de diálogos entre o Sul do Norte (@s Queers of Coloure a diáspora queer nos EUA e na Europa) e o Sul do Sul, ou seja, as realidades da América Latina e da África. Nesse sentido, manter a crítica radical ao "cânone epistêmico ocidental" (Grosfoguel, 2010:457) e brancocêntrico não seria incompatível com o fato de nos direcionarmos para conjuntos teóricos oriundos de contextos geograficamente situados no hemisfério Norte, mas simbolicamente $e$ metaforicamente associados a uma perspectiva epistêmica subalterna, anti-imperialista e anticolonial. A esse propósito, nos fundamentamos no texto da feminista indiana, Chandra Mohanty, Under Western Eyes Revisited, no qual a autora rejeita as dicotomias entre Sul/Norte, Terceiro Mundo/Ocidente, enquanto expressões de lugares geograficamente opostos, para considerar o valor metafórico e político que esses termos contêm. Norte e Sul devem ser, ao contrário, compreendidos, segundo a autora, como expressão de "minorias e maiorias sociais - categorias baseadas na qualidade de vida conduzida por determinadas populações $e$ comunidades, tanto no Norte como no Sul" (Mohanty, 2003:506).

A preocupação com uma leitura transversal, interseccional, não identitária e não elitista da condição queer, que critica sua simples identificação a partir da orientação sexual, aparece claramente nos textos de teóric@s queers african@s. A produção sobre questões queers e sobre sexualidades não normativas, na África, está crescendo e apresenta leituras complexas e variadas, testemunhando uma grande efervescência. Por isso, acreditamos que um diálogo entre as produções africanas e latino-americanas, no campo da teoria queer, seria de extrema importância para consolidar esse campo de estudo e de militância a partir da perspectiva do Sul. 
Entre essas produções africanas, destacamos a coletânea organizada pela acadêmica feminista ugandense, Sylvia Tamale, African Sexualities, o Queer African Reader, editado pela feminista nigeriana Sokari Ekine e pela egípcia Hakima Abbas e a coletânea Reclaiming Afrikan. Queer perspectives on sexual and gender identities, editado pela militante e acadêmica sul-africana, Zethu Matebeni. A primeira coletânea não discute uma perspectiva queer, mas é orientada pelo objetivo de "mapear e desfazer os mapas das sexualidades africanas" (Tamale, 2011:5), ou seja, de colocar em evidência a pluralidade e a complexidade das abordagens, tanto hegemônicas como dissidentes, da sexualidade na África. Examinando as diferentes facetas da esfera sexual, enquanto um local particularmente denso de relações de poder, mas também de fenômenos de contestação social e política, essa coletânea pretende questionar e problematizar as concepções essencialistas, estereotipadas e rígidas que querem reduzir as culturas africanas - suas representações e experiências das sexualidades - a um bloco homogêneo e sem diversidade. Escreve, a esse propósito, Sylvia Tamale, na introdução geral ao Reader.

falamos de sexualidades ao plural para reconhecer as estruturas complexas dentro das quais a sexualidade é construída, e para reconhecer suas articulações plurais. A noção de uma sexualidade homogênea e não modificável para todos os africanos está fora de discussão, não somente em relação às realidades das vidas, das experiências, das identidades, mas também em relação ao ativismo $e$ às pesquisas atuais (Tamale, 2011:2).

A segunda coletânea, o Queer African Reader, publicada em 2013, reúne textos de acadêmic@s, escritor@s, ativistas politic@s, artistas african@s engajad@s nas lutas das populações LGBTIQ e que discutem perspectivas teóricas próximas às que definimos como Queers of Colour. De um ano posterior, Reclaiming Afrikan (2014), também visa a reunir diferentes perspectivas queer no 
continente. Como destacam Zethu Matebeni e Jabu Pereira, na introdução, muitas

das pessoas nesse volume se enxergam como queer - uma categoria que estamos pront@s a reconhecer plenamente $e$ a entender no continente. Nós nos apropriamos, ao mesmo tempo, da Afrika e do Queer, para afirmar as identidades sexuais $e$ de gênero $e$ as posições que são comumente humilhadas e violadas pelo preconceito e o ódio. A própria Afrika é, em si mesma, sempre separada da pessoa queer (Matebeni; Pereira, 2014:7).

Essas coletâneas nascem em um momento em que as comunidades LGBTIQ africanas enfrentam várias dificuldades, devido à imposição de legislações repressivas, expressão de fundamentalismos tradicionais e religiosos, mas também a um quadro internacional atravessado por lógicas neocolonizadoras. Como destaca Sokari Ekine (2013), no artigo publicado no Queer African Reader, "Contesting narratives of queer Africa"9, @s ativistas e teóric@s queers african@s são constantemente confrontad@s com duas narrativas opostas, mas interligadas, que dominam as discussões ao redor das sexualidades africanas: a do universalismo ocidentalcêntrico, promovido pelas agendas LGBT globais de cunho neoliberal, que afirmam a imagem de uma África obsessivamente homofóbica, e a dos essencialismos culturalistas locais que reivindicam que as sexualidades queer são estrangeiras $e$ importadas e que, consequentemente, não existe homossexualidade na África. A construção da teoria e do ativismo queer na África foi possível a partir da rejeição dessas duas retóricas e das armadilhas que elas produzem no contexto das pós-independências, em que sobrevivem os vínculos coloniais e o campo das sexualidades e do gênero se torna facilmente um instrumento para reforçar as relações de poder entre Norte e Sul

9 Esse artigo foi recentemente publicado em tradução portuguesa pela revista Cadernos de Gênero e Diversidade (2016). 
global. Como escreve Sokari Ekine, em artigo publicado no Queer African Reader, as

tensões postas por essas duas narrativas apresentam um desafio estratégico sério para as políticas queer africanas anticolonialistas, presas em vários pontos entre as metanarrativas do imperialismo LGBT e o fundamentalismo religioso homofóbico, de um lado, e as contemporâneas construções internas da sexualidade e do gênero, de outro lado (Ekine, 2013:78).

Como constatamos no caso da teoria Queer of Colour, o queer africano se compreende como muito mais do que como um simples discurso sobre sexualidades $e$ identidades de gênero não normativas. Ele investe em uma ampla reflexão política sobre o mundo contemporâneo, as tensões do sistema neoliberal, aos níveis local e global, e, particularmente, sobre os efeitos das novas e múltiplas relações de poder que atravessam o continente africano. Como precisam Sokari Ekine e Hakima Abbas, na introdução ao Reader,

usamos o termo queer aqui e no título para denotar um quadro político, mais do que uma identidade de gênero ou um comportamento sexual. Usamos queer para sublinhar uma perspectiva que abraça a pluralidade sexual e de gênero e visa a transformar, revisar e revolucionar a ordem africana mais do que procurar assimilá-la no contexto hetero-patriarcal capitalista opressivo. Queer é a nossa postura dissidente, mas o usamos aqui com conhecimento das limitações dessa terminologia em relação às nossas realidades africanas neocoloniais (Ekine; Abbas, 2013:3-4).

A partir dessa leitura, somente uma compreensão interseccional da situação das minorias sexuais, nos países africanos, pode dar conta da complexidade dos fatores políticos envolvidos. Por isso, @s autor@s do Queer African Reader concordam em afirmar que, para enfrentar os fundamentalismos 
religiosos e culturais que pretendem definir, de forma essencialista e estática, o que é verdadeiramente africano e o que não é, para questionar o "pânico heterossexual" (Ossome, 2012:35) e seu mito da "heterossexualidade exclusiva dos africanos" (Ossome, 2012:34), os discursos e as intervenções promovidas pelos países do Norte $e$ suas embaixadas - inclusive pelas ONGs que representam a "Internacional Gay" (Massad, 2007, apud Elkine; Abbas, 2012:1; Elkine, 2012:85) - revelam-se insuficientes e mesmo nocivos para a causa queer, nos contextos locais africanos. Sustentando-se no mito da homogeneidade dos interesses e das reivindicações das populações LGBT, a partir de um modelo elitista euro-americano, essas ações desconhecem, na maioria dos casos, os contextos africanos e se revertem facilmente em uma caça à homofobia do Sul global ou em uma espetacularização da "homofobia africana como um único fenômeno geográfico, desconectado das histórias locais e globais e essencialmente inerentes" (Elkine, 2012:85) àqueles contextos. Nesse ponto, a teoria queer africana recupera as reflexões elaboradas pela plataforma Queer of Color ao criticar a retórica do excepcionalismo sexual do Ocidente, cujas campanhas salvacionistas, supostamente voltadas para libertar as vítimas da homofobia $e$ do autoritarismo das sociedades africanas e de seus líderes políticos e religiosos, representam um braço poderoso do imperialismo neoliberal ocidental. Segundo Sokari Ekine e Hakima Abbas, as intervenções dos governos ocidentais que ameaçam a retirada de ajudas humanitárias para os países que não respeitam os direitos das minorias sexuais geram uma situação paradoxal e profundamente ambígua, na qual os direitos dessas minorias acabam sendo interpretados em oposição aos direitos e interesses sociais e econômicos das populações locais e à luta anticolonial. Como, então, seria possível que tal estratégia possa realmente trazer benefícios para as pessoas queer africanas? O ponto é que @s queers african@s não são somente queers, mas também african@s e suas reivindicações não são unicamente aquelas dos queers euro-american@s. Suas lutas se unem a outras lutas das populações africanas e à necessidade de enfrentar os 
efeitos negativos do sistema capitalista ocidental e das políticas neocoloniais nos contextos locais.

Nessa direção, como afirma Lyn Ossome, é preciso rejeitar as políticas identitárias LGBT que, homogeneizando $e$ naturalizando os grupos sociais diferentes, são incapazes de dar conta da solidariedade e da possibilidade de alianças fronteiriças entre esses distintos grupos. As identidades são, ao contrário, sempre plurais e interseccionais.

A perpetuação de noções homogeneizantes que subsomem
todas as populações queer embaixo de uma categoria
alienante e polêmica, é, de certa forma, estranha. O mito
segundo o qual a homossexualidade é elitista (...) tenta
fechar a identidade sexual em relação a outras intersecções
com as subjetividades de gênero, raciais ou étnicas e, ao
fazer assim, restringe o campo de temas sobre os quais as
minorias sexuais podem sustentar suas lutas. O efeito dessa
posição é de negar, para os LGBTI pobres, o suporte e a
solidariedade de outros grupos, similarmente
marginalizados do ponto de vista econômico (Ossome,
2012:36).

A perspectiva queer africana afirma a necessidade de reestabelecer uma plataforma comum e intersectada dos ativismos, voltada para a construção de uma sociedade mais justa $e$ inclusiva.

Podemos resumir aqui, brevemente, as respostas elaboradas pelas abordagens queer africanas diante das duas narrativas produzidas pelos fundamentalistas internos, de um lado, e pelas organizações internacionais ocidentais, de outro. Embora aparentemente opostas e expressão de interesses e de sujeitos políticos diversos, essas duas retóricas apresentam um caráter essencialista, fixo e, como tal, nocivo para o desenvolvimento da agência (agency) queer no continente. Por isso, segundo@s autor@s do Queer African Reader, essas duas lógicas precisam ser rejeitadas. A homossexualidade não é algo anti-africano (unAfrican), supostamente oposto a uma origem pura e autêntica do 
ser africano ou da cultura africana. É preciso, porém, descolonizar a teoria queer e dar mais visibilidade para a teoria queer africana, assim, questionando o modelo ocidental, branco euro-americano (Clarke, 2012). Se, como afirma Douglas Clarke, o "Ocidente se colocou na posição de autoridade para o conhecimento da experiência homossexual" (Clarke, 2012:177), a teoria queer africana pretende dar voz para outros modelos de queerness, para outros conhecimentos e outras experiências da homossexualidade. Ou seja, segundo esse autor, a Africa tem de criar e desenvolver sua própria teoria queer $e$ suas formas de viver a homossexualidade. Assim, da mesma forma, a homofobia não pode ser considerada como uma atitude inerente à cultura africana, aqui novamente entendida como supostamente homogênea, imutável e, dessa vez, reduzida ao outro orientalizado do Ocidente. A imagem de uma África intrinsecamente homofóbica, machista e sexualmente atrasada, acompanha-se da representação dos países ocidentais euro-americanos como sexualmente evoluídos, defensores dos direitos das minorias sexuais e das mulheres.

Consideramos, enfim, que a tradução, o conhecimento e a divulgação desses textos no Brasil $e$ no continente latinoamericano é de suma importância para o desenvolvimento de um diálogo intelectual e militante Sul-Sul, ao redor da dissidência sexual e de gênero e para a implementação de novas estratégias de reflexão e de luta, centradas em uma perspectiva descolonial $e$ anti-imperialista.

\section{Conclusão}

Partimos do texto de Yuderkys Espinosa Miñoso sobre a tradução da teoria queer nos contextos latino-americanos e da consideração da feminista dominicana sobre a ausência de sujeitos e de corpos racialmente marcados nos espaços da diversidade sexual. Essa autora considera que os estudos queer chegaram para América Latina por meio de grupos restritos e hegemônicos em termos de raça e de classe. Diferentemente das teorias sobre 
sexualidades, o campo feminista latino-americano conseguiu se constituir de forma menos hegemonizada, pelo diálogo com as correntes do chamado Black Feminism.

\begin{abstract}
Precisamos reconhecer - escreve Yuderkys - que muito cedo, no feminismo latino-americano destacou-se parte das preocupações enunciadas pelas feministas não brancas $e$ lésbicas articuladas nos Estados Unidos. As denúncias dos privilégios das mulheres brancas de classe média $e$ heterossexuais foram formuladas, intermitentemente, a partir da metade dos anos 1980, pelo feminismo latinoamericano e caribenho comprometido com os setores populares (Miñoso, 2015:32).
\end{abstract}

O caso do Brasil é, segundo essa autora, emblemático, ao tecer laços teóricos e políticos entre o movimento local das mulheres negras $e$ as feministas negras norte-americanas, tornando possível uma pluralidade de lugares não hegemônicos de fala e quebrando o colonialismo discursivo do Norte.

Em conclusão, gostaríamos de colocar uma questão que não foi possível abordar, aqui, de forma detalhada, mas que possa ser objeto de um próximo estudo, a saber se, na luz da crítica Queer of Colour, seria possível uma aproximação entre a perspectiva descolonial, de um lado, e a pós-colonial, de outro, tradicionalmente entendidas como diferentes e distantes uma da outra. Uma primeira resposta positiva nos parece possível, a partir da análise do caráter transnacional da crítica Queer of Colour e suas reivindicações. ${ }^{10}$ Isso constituiria, porém, o objeto de uma nova pesquisa.

Por enquanto, neste texto, tentamos percorrer os caminhos da teoria queer em direção ao Sul global e, particularmente, o

\footnotetext{
${ }^{10}$ Nesse sentido, nos parecem convergir, por exemplo, as contribuições de Bakshi, Jivraj e Posocco (2016), mas também as análises dos movimentos Queer/Two-Spirit, interpretados por autores como Qwo-Li Driskill, Chris Finley, Brian Joseph e Scott Lauria Morguensen (2011), nos Estados Unidos e no Canadá, e por Estevão Fernandes (2015, 2017a e 2017b), no Brasil.
} 
latino-americano e o africano, colocando a questão de se, a partir das elaborações crítico-teóricas dos chamad@s Queers of Color, não poderíamos identificar uma outra genealogia desse campo de estudo e abrir novas possibilidades de diálogo e de encontro não hierárquico e vertical com os campos latino-americano e africano da dissidência sexual. Nosso esforço foi, então, apresentar algumas das reflexões e das figuras mais significativas desse campo de produção teórica e militante, esperando que essas possam ser, em breve, disponibilizadas em tradução portuguesa e/ou espanhola, circulando, de forma mais visível, entre os diferentes Suis, geográficos e metafóricos, do mundo.

\section{Referências bibliográficas}

ANZALDÚA, Gloria; MoRAGA, Cherrie (org.). This Bridge called my back. Writings by radical women of color. Boston, Kitchen Table, 1981.

ANZALDÚA, Gloria. La consciência de la mestiza/Rumo a uma nova consciência. Revista Estudos Feministas 13(3), Florianópolis, 2005, pp.704-719.

. Borderlands/La Frontera. The New Mestiza. San Francisco, Aunt Lute Books, 2012.

BACCHETTA, Paola; FAlQUeT, Jules; AlARCóN, Norma. Introduction au "Théeories féministes et queers décoloniales: interventions chicanas e latinas états-uniennes". Les Cahiers du CEDREF, Paris, n 18, 2011, pp.7-40.

BACCHETTA, Paola. Co-formações/co-produções: considerações sobre poder, sujeitos subalternos, movimentos sociais e resistência. In: TORNQUIST, Carmen Susana et alii. Leituras de resistência: corpo, violência, poder. Florianópolis, Editora Mulheres, 2009.

. Se la nazione (indù) esilia il queer. In: BACCHETTA, Paola; FANTONE, Laura. Femminismi queer postcoloniali. Critiche transnazionali all'omofobia, all'slamofobia e all'omonazionalismo. Verona, Ombre Corte, 2015, pp.121-149. 
BAKSHI, Sandeep; JIVRAJ, Suhraiya; POSOCCO, Silvia. Decolonizing sexualities. Transnational perspectives, critical interventions. Oxford, Counterpress, 2016.

BOURCIER, Marie-Hélène/Sam. Entrevista realizada por Pedro Paulo Gomes Pereira. CULT, n 205, 2015, pp.11-15.

Cervulle, Maxime; ReEs-RoberTs, Nick. Homo Exoticus. Race, classe et critique queer. Paris, Armand Colin, 2010.

DE LAURETIS, Teresa. Théorie queer et cultures populaires. De Foucault à Cronenberg. Paris, La Dispute, 2007.

DrISKILl, Qwo-Li; FINLEY, Chris; GILley, Brian Joseph; MorguenSEN, Scott Lauria. Queer Indigenous Studies. Critical Interventions in Theory, Politics, and Literature. University of Arizona Press, 2011.

EKINE, Sokari. Narrativas contestadoras da África Queer. Cadernos de Gênero e Diversidade, vol. 2, n² 2, Salvador-BA, 2016, pp.10-14.

ABBAS, Hakima (org.). Queer African Reader. Dakar/Nairobi/Oxford, Pambuzuka Press, 2013.

El TAYeB, Fatima. European Others. Queering. Ethnicity in Postnational Europe. Minneapolis, University of Minnesota Press, 2011.

. Lesbian of Color Activism and Racist Violence in Contemporary Europe. In: BAKSHI, Sandeep; JIVRAJ, Suhraiya; POSOCCO, Silvia. Decolonizing sexualities. Transnational perspectives, critical interventions. Oxford, Counterpress, 2016, pp.154-169.

ENG, David; HALBERTAM, Judith; MuNOZ, Esteban. What's Queer about queer studies now? (Introduction). Durham/London, Duke University Press, 2005, pp.1-17.

FERGUSON, Roderick. Aberrations in Black. Towards a Queer of Color Critique. University of Minnesota Press, 2003.

. Race-ing homonormativity: citizenship, sociology, and gay identity. In: JOHNSON, Patrick; HENDERSON, Mae G. (org.). Black Queer Studies. A critical Anthology. Durham/London, Duke University Press, 2005, pp.52-67.

FERNANDES, Estevão. Ativismo homossexual indígena: Uma análise comparativa entre Brasil e América do Norte. Dados. Revista de Ciências Sociais, vol. 58, n 1, Rio de Janeiro, 2015, pp.257-294. 
Quando existir é resistir: Two-Spirits como crítica colonial. Revista de Estudos e Pesquisas sobre as Américas, vol. 11, $\mathrm{n}^{\circ} 1$, 2017a, pp.100-122.

. Existe índio gay? A colonização das sexualidades indígenas no Brasil. Curitiba, Editora Prismas, 2017b.

Figueiredo, Ângela. Carta de uma ex-mulata a Judith Bulter. Periódicus, vol. 1, n 3, Salvador, 2015, pp.152-169.

GROSFOGUEL, Ramón. Para descolonizar os estudos de economia política $e$ os estudos pós-coloniais: transmodernidade, pensamento de fronteira e colonialidade global. In: SANTOS, Boaventura de Sousa, Meneses, Maria Paula. Epistemologias do Sul. São Paulo, Cortez Editora, 2010, pp.383-417.

HALBERSTAM, Judith. Shame and Gay White Masculinity. In: HALBERSTAM, Judith; ENG, David; MuNOZ, Esteban. What's Queer about queer studies now? (Introduction). Durham/London, Duke University Press, 2005, pp.219-233.

HALBERSTAM, Judith/Jack. Repensando o sexo e o gênero. In: MISKOLCI, Richard; PElúCIO, Larissa. Discursos fora da ordem. Sexualidades, saberes e direitos. São Paulo, Annablume, 2012, pp.125-137.

HARITAWORN, Jin. Loyal Repetitions of the Nation: Gay Assimilation and the War on Terror. Postcolonial sexuality (3), 2008. [http://www.darkmatter101.org/site/wp-content/uploads/pdf/3-

haritaworn_loyal_repetitions_of_the_nation.pdf - acesso em: 07 nov. 2015].

. Women's rights, gay rights and anti-Muslim racismo in Europe. European Journal of Women's Studies, 19, 2012, pp.73-80.

- Além do ódio: metonímias queer para crime, patologia e antiviolência. Meritum, Belo Horizonte, vol. 9, n 2, 2014, pp.189261.

; BACCHETTA, Paola. I molti transatlantici: omo-nazionalismo, onotransnazionalismo, teorie e pratiche femministe-queer-trans di colore: un dialogo. In: BACCHETTA, Paola, FANTONE, Laura. Femminismi queer postcoloniali. Critiche transnazionali all'omofobia, all'islamofobia e all'omonazionalismo. Verona, Ombre Corte, 2015, pp.179-198. 
IRINEU, Bruna Andrade. Homonacionalismo e cidadania LGBT em tempos de neoliberalismo: dilemas e impasses às lutas por direitos sexuais no Brasil. Em Pauta, vol. 12, n 34, Rio de Janeiro, 2014, pp.155-178.

JoHnson, Patrick; Henderson, Mae G. (org.). Black Queer Studies. A critical Anthology. Durham/London, Duke University Press, 2005.

MASSAD, Joseph. Desiring Arabs. Chicago, University of Chicago Press, 2007.

MATEBENI, Zethu; PeREIRA, Jabu. Preface. In: MATEBENI, Zethu. Reclaiming Afrikan. Queer perspectives on sexual and gender identities. Athlone, Modjaji Books, 2014, pp.7-9.

MiÑOSO, Yuderkys Espinosa. El futuro ya fue: una critica a la idea del progreso en las narrativas de liberación sexo-genérica y queer identitarias en Abya Yala. In: FerRERA-BAANQUET, Raúl Moarquech. Andar Erótico Decolonial. Buenos Aires, Ediciones del Signo, 2015, pp.21-35.

MISKOLCI, Richard. A Teoria Queer e a Sociologia: o desafio de uma analítica da normalização. Sociologia, ano 11, n 21, 2009, pp.150182.

; Pelúcio, Larissa. Discursos fora da ordem. Sexualidades, saberes e direitos. São Paulo, Annablume, 2012.

MoHANTY, Chandra. Under Western Eyes Revisited. Signs, vol. 28, n 2 , 2003, pp.499-535.

PelúCIO, Larissa. Subalterno quem, cara pálida? Apontamentos às margens sobre pós-colonialismos, feminismos estudos queer. Contemporânea, Salvador, vol. 2, n 2, 2012, pp.395-418.

- Traduções e torções ou o que se quer dizer quando dizemos queer no Brasil. Periodicus, vol. 1, $\mathrm{n}^{\circ}$ 1, Salvador, 2014 [http://www.portalseer.ufba.br/index.php/revistaperiodicus/article/view /10150/7254 - acesso em: 10 ago 2015].

PUAR, Jasbir. Terrorist Assemblages. Homonationalism in Queer times. Duke Univrsity Press, 2007. 
. Homonacionalismo como mosaico: viagens virais, sexualidades afetivas. Revista Lusófona de Estudos Culturais, vol. 3, n 1 , Aveiro, 2015, pp.297-318.

. "Prefiro ser um cyborgue a ser uma deusa": interseccionalidade, agenciamento e política afetiva. Meritum, vol. 8, n 2, 2013, pp.343370 .

SANDOVAL, Sheila. Féminisme du tiers-monde états-uniens: mouvement social différetiel. Les Cahiers du CEDREF $\mathrm{n}^{\circ}$ 18, 2011 [https://cedref.revues.org/686 - acesso em: 20 jul 2015].

TAMAle, Sylvia (org.). African Sexualities. A Reader. Dakar/Nairobi/Oxford, Pambakuza Press, 2011. 